\title{
Microwave Power Absorption Evaluation of River Shell Particles Reinforced Polyester Composite
}

\author{
Isam Salah Hameed ${ }^{1 *}$, Hamid M. Mahan², Ahmed Salah Hameed $^{3}$ \\ 1 Department of Electronic, College of Engineering, University of Diyala, P.O.BOX-1, College of Engineering Branch, Ba'quba Mail \\ Office, Diyala, Iraq \\ 2 Technical Institute of Baquba, The Middle Technical University (MTU), Baghdad 10001, Iraq \\ ${ }^{3}$ Department of Computer, College of Engineering, University of Diyala, P.O.BOX-1, College of Engineering Branch, Ba'quba Mail \\ Office, Diyala, Iraq \\ * Corresponding author, e-mail: isamud84@gmail.com
}

Received: 24 April 2019, Accepted: 30 October 2019, Published online: 19 November 2019

\begin{abstract}
The objective of this research is to analyze the microwave power absorption properties of Unsaturated Polyester Resin (UPR) composite reinforced with micro size river-shell with an aim to figure out the new formed composites with the best microwave power absorption scenario. The composites were prepared by using river shell powder in micro-particle size as a filler material with unsaturated polyester composites. Using free-space transmission technique and within the $\mathrm{x}$-band frequency range, the microwave power absorption properties were studied with varied percentages of river shell powder being loaded into the unsaturated polyester composites. River shells were introduced in an 50 microns particle size powder which was mixed in different weight percentages of 5, 10, and $15 \%$ of a $12 \mathrm{~cm}$ square shape side length composite sample along with a thickness of $4 \mathrm{~mm}$ for each sample. The test specimens were prepared using the pre-mentioned weight amounts after mixing them with the Unsaturated Polyester Resin (UPR) compositions and in accordance with ASTM standard. Number of teste samples are four represented by pure, $5 \%, 10 \%$, and $15 \%$ of river-shell reinforced polyester composites. It has been found that the $5 \%$ is the case when maximum power absorption presents higher levels than other loading percentages. Therefore, such kind of composites can be established under focus in those applications at which their trends is about necessity and importance of microwave power absorption.
\end{abstract}

\section{Keywords}

free-space, microwave power absorption, river-shell, Unsaturated Polyester Resin (UPR)

\section{Introduction}

The feature of polymer composites ability to behave both metallic and plastic properties when cured by different fillers, puts such material to be usable by different applications whether it was electrical or mechanical ones. Besides, such polymer type material may be regarded as a feature-controlled material. In other word, polymer material may be enhanced with the ability to controlling some of electrical and thermal characteristics depending on the filler type as well as filler size or shape [1].

Combing more than one material gives rise to new composite materials with new properties and applications. The world using epoxy or polyester polymers to be reinforced by other substances, is of the most widely applied composite materials [2].
The great role of polymer composites is around the ability of creating new materials with prior considerations to fit and suit specific designs. As a result, many researches have been made to come up with new materials with superior attributes and strength [3].

In the field of bio-gradable polymer composites, Natural Fillers (NF) like sea-shell, egg-shell, flax-shell, and hemp have better advantages than traditional fillers. For instance, such materials are regarded as environment-friendly fillers that would have a great role in reducing pollution and greenhouse-emissions. Besides, Natural Fillers tend to be good substituting material in the world of reinforcing as they tend to be economic-friendly, good hardness features, low density, and non-abrasive to manufacturing 
equipment [4]. Among of various filler types, river shell could be considered as one of the interesting material when used as filler in biodegradable polymer composites. It was noticed that river shell provided high tensile strength, improved hardness values, enhanced mechanical properties, and high impact strength specifically when it is used by $5 \%$ weighing amount [5]. Therefore, it has been important to investigate the effect of using this materials, as filler material in the microwave filed.

In spite of applying many researches on natural material matrix composites, no one has used river-shell as a filler material to be tested under microwave effects.

The test specimens were prepared using the pre-mentioned weight amounts after mixing them with the polyester resin compositions and in accordance with ASTM standard. It has been found that the $5 \mathrm{wt} \%$ is the case when maximum power absorption readings levels indicates higher values than other loading percentages. Therefore, such kind of composites can be put under focus in those applications at which their trends is about necessity and importance of microwave power absorption.

\section{Materials and methods}

\subsection{Materials}

\subsubsection{Unsaturated Polyester Resin}

Polyester resin is on the thermoplastic resin types. Chemically, it is prepared by the reaction of two-based acid with an aliphatic diol, which is also called glycol. Although it has good thermal resistance of high temperatures of about $176{ }^{\circ} \mathrm{F}$, polyester may lose cohesion and gradually fail at very high temperature. Also, polyester has a great resistance to chemical materials such as solvents, acids, and salts. Also, it is famous of its excellent electrical resistance as well as low cost property. Polyester applications come in different fields of molding structure such as manufacturing molds and component parts of aircraft bodies, automobiles and other industries. Fig. 1 shows chemical composition of unsaturated polyesters [6].

\subsubsection{River shells}

In this paper, empty river shells were collected from Diyala river bank which is located in Iraq, Baquba city. An in situ photo is shown by Fig. 2. Later, shells were finely cleaned

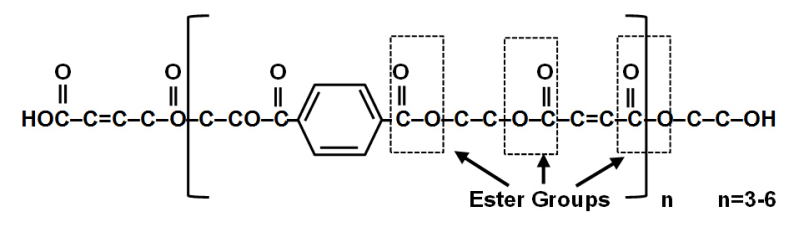

Fig. 1 Chemical composition of unsaturated polyesters

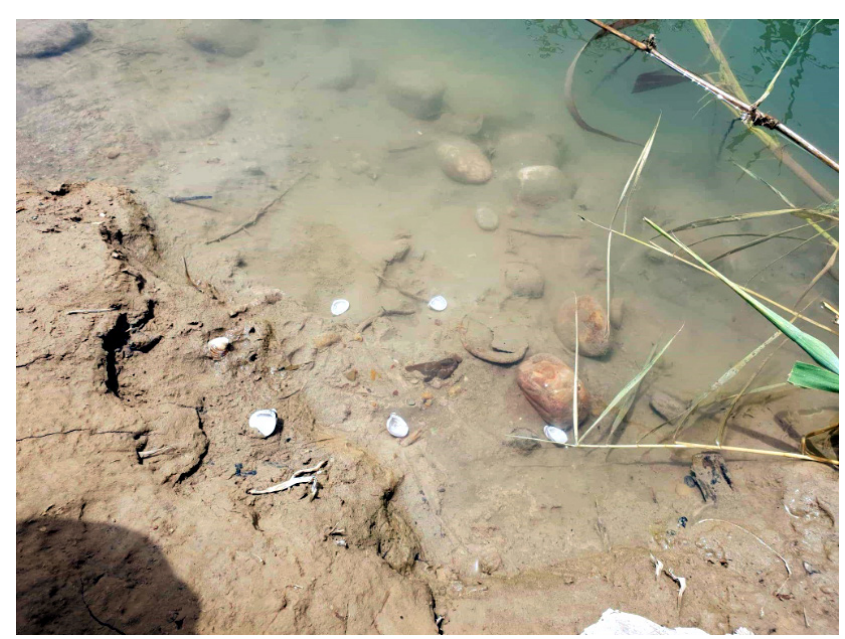

Fig. 2 An in situ location of river shells

to make sure of removing any type of dirt or organic substances. Fig. 3 shows samples of used river shells along with their ground into powder form. Cleaned shells were left to dry under sunlight exposure as well as using heat process by putting them in special drying furnace at $55^{\circ} \mathrm{C}$.

Having been dried for adequate time, cleaned and dried river shells were manually crushed by using mortar and pestle implements as a first step which is then followed subdued to sieve analysis for grain powder size measurement.

Sieve analysis was made so as to from the intended powder size which was about 50 microns. Micro size powder was used to enrich the polyester and be as the filler content.

Regarding the chemical composition of river shells, the material spectra being shown in this paper is an indication to the most relevant compounds that might be included in the river shell composition. Actually, an examine process was made to obtain this spectra. This process was implemented in the ministry of science and technology research laboratories in our country. Calcium is the dominant element since examined material is originally river shell which usually contains Calcium.

Fig. 4 presents an examine process for river shell chemical compounds.

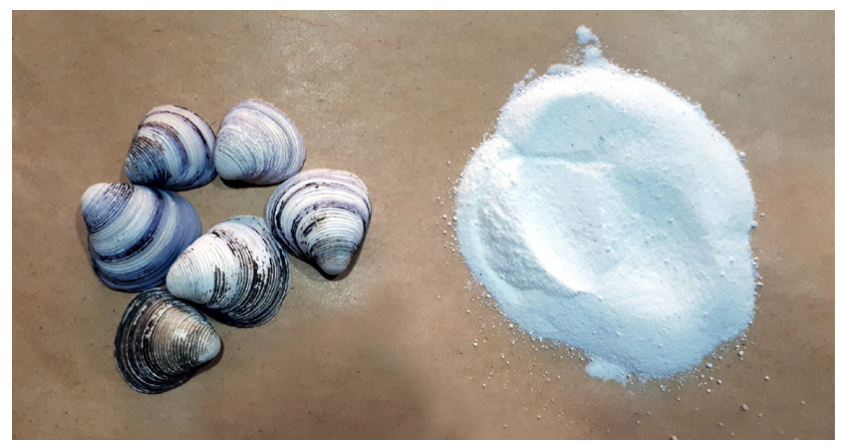

Fig. 3 River shells samples and their ground into powder form 


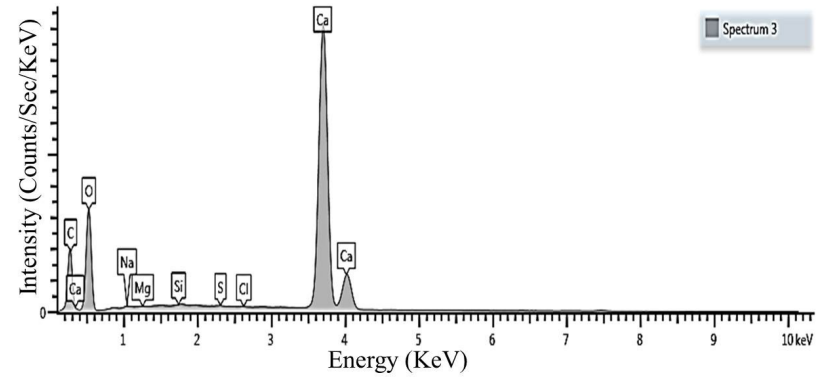

Fig. 4 Chemical compositions of the river shell

\subsection{Composite preparation}

First of all, molds were prepared as shown by Fig. 5 where bars of glasses with specific thickness values are arranged to form the square shape mold. Size of samples is determined by selecting the desired length and bar thickness as $12 \mathrm{~cm}, 0.4 \mathrm{~cm}$ respectively.

Two types of samples were molded as pure and reinforced samples. Firstly, pure polyester samples were formed without adding any river-shell powder contents by pouring 1 amount of the hardener into 2 amounts of the resin. With a digital scale of readability of $0.01 \mathrm{~g}$, accurate weights were gained. Having been homogenously mixed, both of resin and hardener were poured into the mold in order to get requested pure samples' size and shape. Secondly, reinforced samples are also prepared in the same manner and with three different filler amounts $5 \%, 10 \%$, and $15 \%$. For example, a sample of $5 \%$ river-shell filler will need to vary the polyester mass so as to form the whole required size. In other words, a 100 gram of composite will contain 95 grams of polyester and 5 grams of reinforcement (river-shell).

In this case, resin and hardener are mixed until slight warm feeling is sensed. This means that chemical reaction between resin and hardener is correctly achieved and the blend is ready for adding filler contents. This time, the mixture is stirred for adequate time until homogeneous solution is formed which is then casted into the prepared

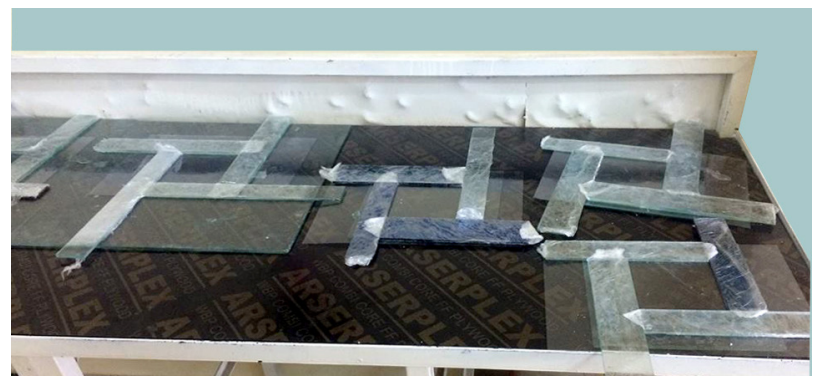

Fig. 5 Glass molds used in sample casting glassy molds and left for 24 hours at the room temperature to assure the hardening process [7].

After preparing material weights, four specimens were prepared according to Table 1.

In general, heat treatment is performed for all samples in a furnace at $60{ }^{\circ} \mathrm{C}$ for a period of 4 hours. This process is so important for the objective of obtaining the cross-linking between polymeric chains, and to remove stress and complete hardness of samples.

The three different reinforcing percentages were molded with a thickness of $(4 \mathrm{~mm})$ since this study focuses on the microwave power absorption evaluation of river shell particles reinforced polyester composite. Fig. 6 shows specimen of the molded samples with three samples for each board composition [8].

\section{Microwave measurements}

\subsection{Free-space transmission system}

In this paper, free-space transmission methods in the frequency range of 9-12 GHz (x-band) were used as the testing technique. Free space method is better than other cavity and waveguide methods since the last ones depend mainly on the careful and accurate pre-designed samples in order to be suitable for testing procedures. In return, free-space method does not require any complex sample preparation. In addition, it is known as a nondestructive and contactless method. Although free space method may experience diffraction errors due to sample edges, these errors can be eliminated by satisfying the condition of using a spot-focusing horn antenna in both transmitter and receiver sides. Besides, accurate direction and steady state receiver system sliding can take part in making such errors highly reduced and neglected [9-11].

Table 1 Designation and Composition of Composites

\begin{tabular}{|c|c|c|}
\hline Sample No. & River shell \% & Polyester \% \\
\hline 1 & 0 & 100 \\
\hline 2 & 5 & 95 \\
\hline 3 & 10 & 90 \\
\hline 4 & 15 & 85 \\
\hline
\end{tabular}

Fig. 6 Three groups of river shell reinforced polyester composite with $12 \mathrm{~cm}$ by $12 \mathrm{~cm}$ area and thickness of $0.4 \mathrm{~cm}$. 


\subsection{Free-space system description}

The system contains two main parts as the transmitter side and the receiver side. Firstly, the transmitter side includes a Gunn diode signal oscillator which is used to feed the whole system with necessary microwave signal. With a negative biasing voltage of 7-10 Volts, this oscillator supplies an $\mathrm{x}$-band signal with a range of frequencies of 8-10.5 GHz. Next to the Gunn comes the isolator as a protection device that would isolate input side form the undesired output signals. A second stage of protection is made by connecting a variable attenuator, which is then connected to a spot focusing horn antenna for the aim of sending the generated $\mathrm{x}$-band microwave signal to be received by the transmitter side.

Secondly, it comes the receiver side represented by the receiving horn antenna that captures the transmitted signal to be furtherly guided through waveguide channel and send to its final destination as it is measured by a special power meter device. Up to this point, the measured power represents the amount of power that was able to incident through all things between the transmitter and receiver side whether it was an empty or filled with Material Under Test (MUT). A wooden holder was used to ensure minimum reflections while testing samples. Also, a sliding technique were carefully installed to smoothly move the receiver side for the aim of assessing variable distances that is needed in investigation near and far-field considerations. Fig. 7 is an in situ photograph of the experimental setup.

\subsection{Method of power absorption}

Two steps are followed in power absorption measuring. At the beginning, the measurement system of the freespace method is installed with the absence of any material between transmitter and receiver horn antennas. This comes to be the essential part of measuring the microwave signal incidence in the space without any kind of obstacles. It is worth to mention that many readings have been recorded to be used in the next step

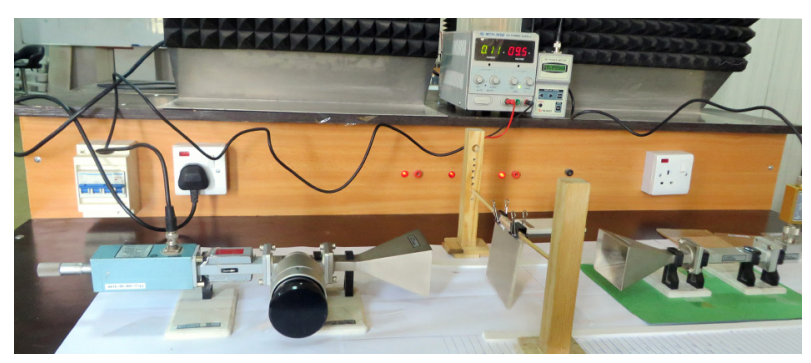

Fig. 7 An in situ photograph of measurement setup in which the effect of microwave on specific material is put under focus. Thus, next step is to insert the Material Under Test (MUT) and to measure the amount of power that is able to incident through the tested sample. Fig. 8 and Fig. 9 depict schematic diagrams of measurement circuits without MUT and with MUT respectively.

From Fig. 8 and as the microwave signal is generated by the Gunn diode, it starts its way toward transmitter horn antenna. At this point, microwave signal can be posed in terms of Eq. (1):

$E=E_{o} e^{j \omega t}$

where $E$ is the value of the signal generated by the oscillator, $E_{o}$ is the maximum voltage value in Volt, and $w$ is the angular frequency in rad.

The Isolator as well as the attenuator add some attenuation as shown in Eq. (2):

$E=k_{1} E_{o} e^{j \omega t}$, for $k_{1}<1$,

where $k_{1}$ represents the attenuation factor for both the variable attenuator and the isolator respectively.

Having been received by the horn antenna at the transmitter side, the signal is further affected by the attenuation factor of the free space (air). As a result, Eq. (3) will better describing the situation of the signal at that point:

$E=k_{1} k_{2} E_{o} e^{j \omega t} e^{-\alpha_{\text {air }}}$,

where $\alpha_{\text {air }}$ is the attenuation factor of air and it is regarded as a very low value while $k_{2}$ is the waveguide attenuation
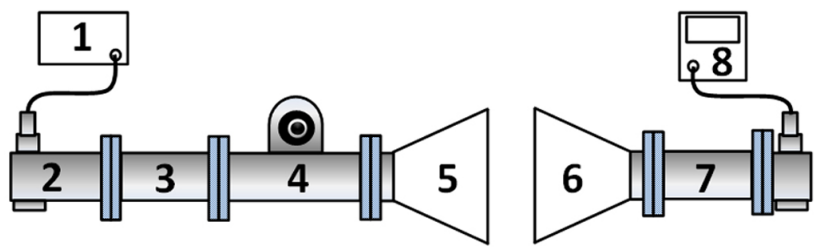

1)Power supply, 2)Gunn diode, 3)Isolator 4)Variable Attenuator, 5)Transmitter, 6) Receiver, 7)Waveguide, and 8)Power meter.

Fig. 8 Measurement setup schematic diagram without MUT

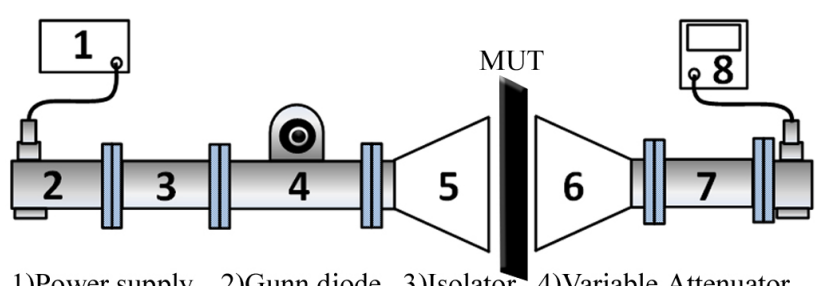

1)Power supply, 2)Gunn diode, 3)Isolator 4)Variable Attenuator, 5)Transmitter, 6) Receiver, 7)Waveguide, and 8)Power meter.

Fig. 9 Measurement setup schematic diagram with MUT 
factor as $k_{2} \ll<1$. By setting $k=k_{1} k_{2}$, Eq. (4) can be a general form for the signal transmitting and receiving when no sample is located between antennas:

$E=k E_{o} e^{j \omega t} e^{-\alpha_{a i r}}$.

At this moment, the measured signal represents the value of received microwave power when there is no sample (without MUT). Along the procedure of paper work, many readings were recorded for different distances between antennas in order to use them in calculating the power absorption amount which is equal to the current power value named as $P_{r o}$ (the received power without MUT) from which $P_{r \text { MUT }}$ (the received power with MUT) is subtracted as shown in Eq. (5) [12]:

$P_{a b s}=P_{r o}-P_{r \mathrm{MUT}}$,

where $P_{a b s}$ is the power absorption.

Fig. 9 shows the second step of measurement procedure. In this case the path of the microwave signal in the transmitter side holds the same equations when no material is inserted.

However, as the signal incidents through the inserted sample, Eq. (4) is edited to the version of Eq. (6):

$E=k E_{o} e^{j \omega t} e^{-\alpha_{a i r}} e^{-T \gamma}$,

where $T$ is the thickness of sample (mm), and $\gamma$ is the propagation constant of the medium (in per meter), and it is given by Eq. (7) below:

$\gamma=\alpha+j \beta$.

By substituting propagation constant value of Eq. (7), can be written in terms of Eq. (8) shown below:

$$
E=k E_{o} e^{j \omega t} e^{-\alpha_{a i r}} e^{-T S(\alpha+j \beta)} .
$$

\section{Results and discussion}

Investigating of research results depends on taking the relation between the microwave power absorption from one side and both of distance between transmit and receive antenna and the ratio of river shell polyester composites' filler from the other side. Since the technique of measurement is the free-space transmission method, results of far-field condition were taken as the main focus to study the real effect of distances and filler amounts on the behavior of microwave signals. The average far-field distance was about $40 \mathrm{~cm}$ in order to achieve far-field condition according to antenna size and operating frequency.
Firstly, the relation between distance and power absorption for frequencies of $9.249,9.305,9.19$, and $9.628 \mathrm{GHz}$ is tabulated for each river shell filler amount as well as the pure polyester composite, and it is shown by Fig. 10 - Fig. 21. From figures, it has been demonstrated that a remarkable indication of high power absorption occurs in the case of $5 \%$ river shell filler amount at each distance value and for each board composition. Although the curve reveals

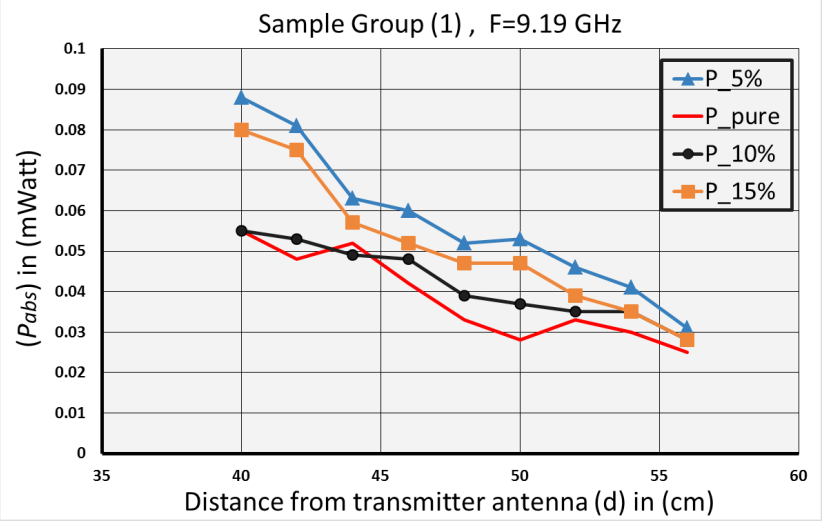

Fig. 10 Power absorption vs. distance at $F=9.19 \mathrm{GHz}$ (Group 1)

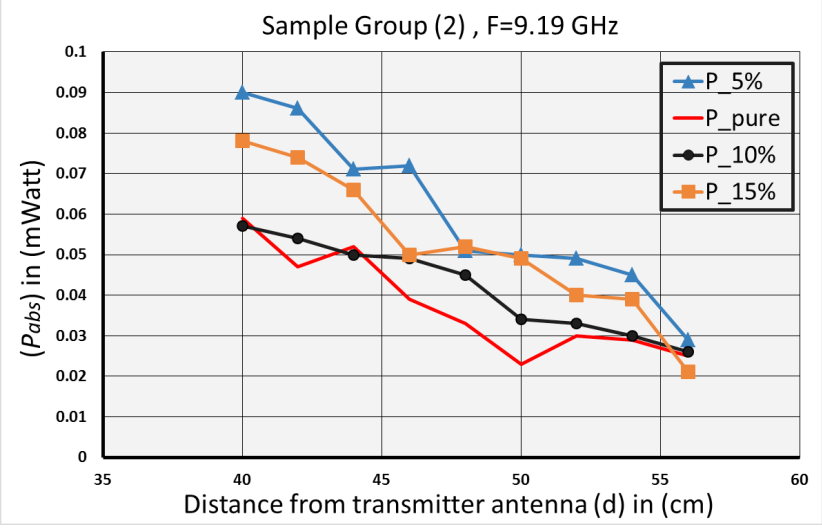

Fig. 11 Power absorption vs. distance at $F=9.19 \mathrm{GHz}$ (Group 2)

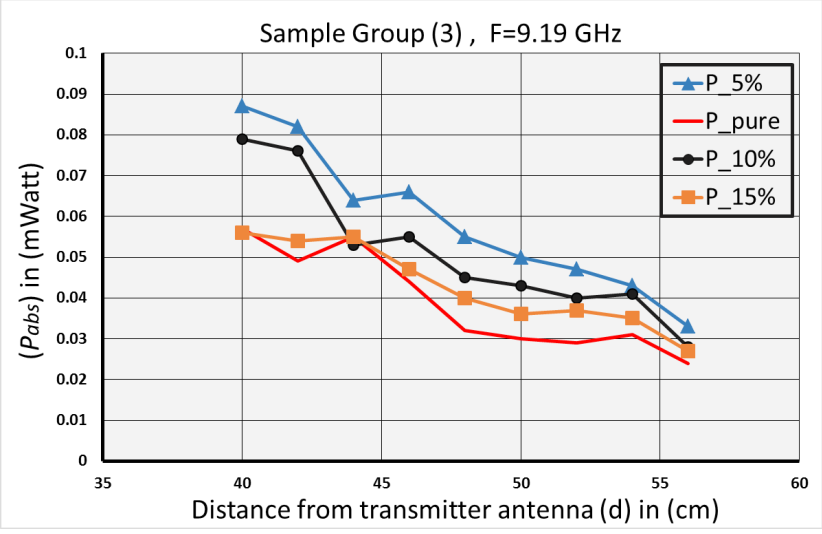

Fig. 12 Power absorption vs. distance at $F=9.19 \mathrm{GHz}$ (Group 3) 


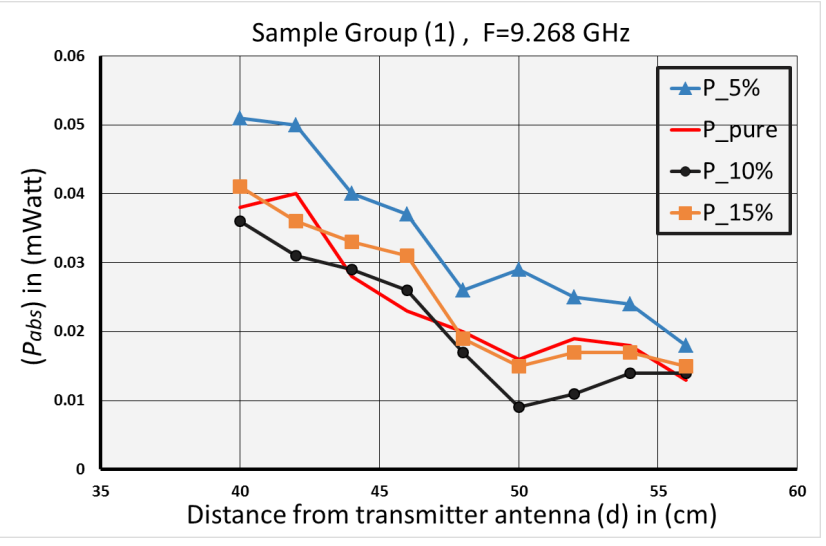

Fig. 13 Power absorption vs. distance at $F=9.268 \mathrm{GHz}$ (Group 1)

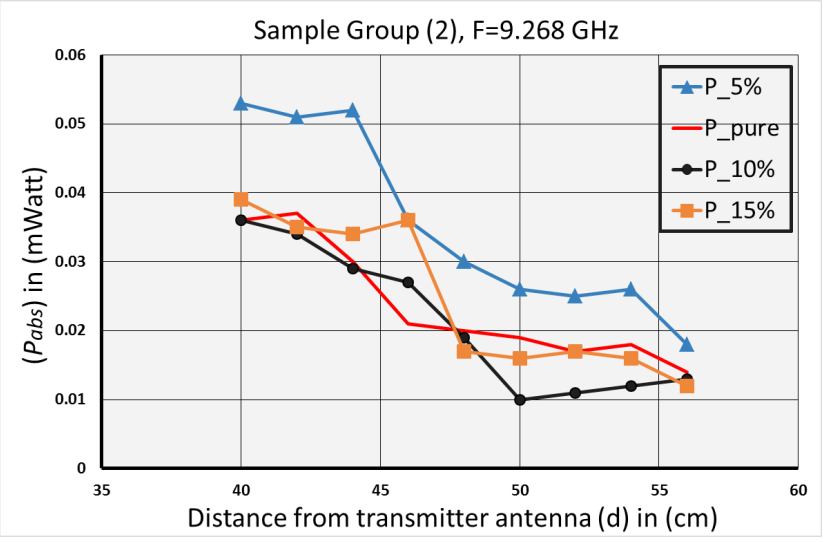

Fig. 14 Power absorption vs. distance at $F=9.268 \mathrm{GHz}$ (Group 2)

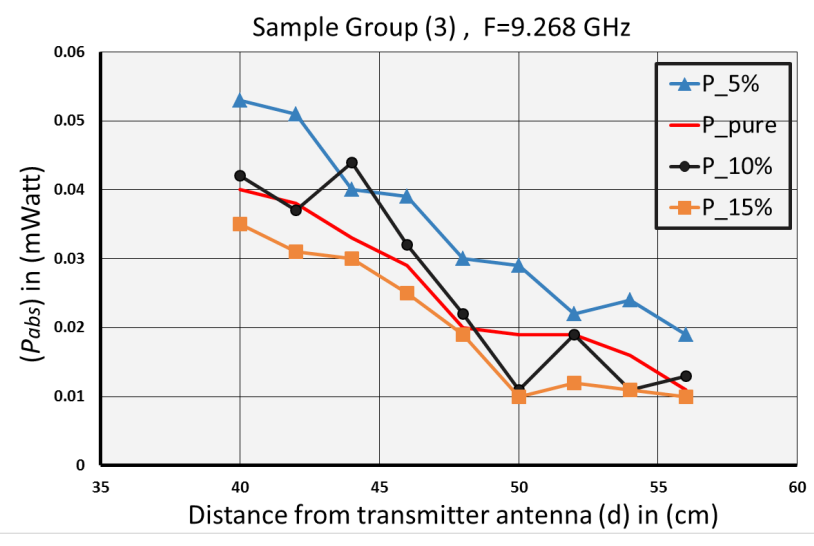

Fig. 15 Power absorption vs. distance at $F=9.268 \mathrm{GHz}$ (Group 3)

a decay as we proceed to larger distance values, it is still clear that the largest values of microwave power absorption is dominant at $5 \%$ amount of river shell. Besides, behavior of wasted power in other filler amounts is not consistent and does not follow a linear and stable increase or decrease.

Secondly, the relation between the ratio of river shell and the value of microwave power absorption at different distance values is shown by Fig. 22 - Fig. 25. This relation

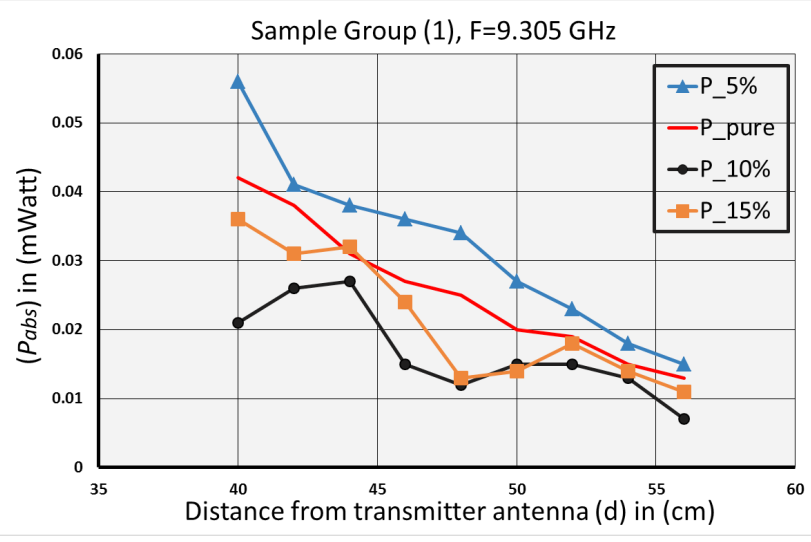

Fig. 16 Power absorption vs. distance at $F=9.305 \mathrm{GHz}$ (Group 1)

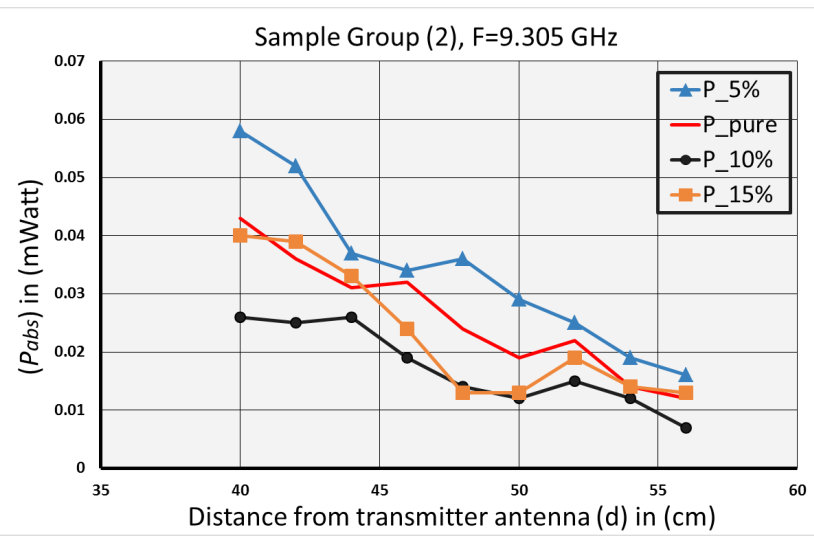

Fig. 17 Power absorption vs. distance at $F=9.305 \mathrm{GHz}$ (Group 2)

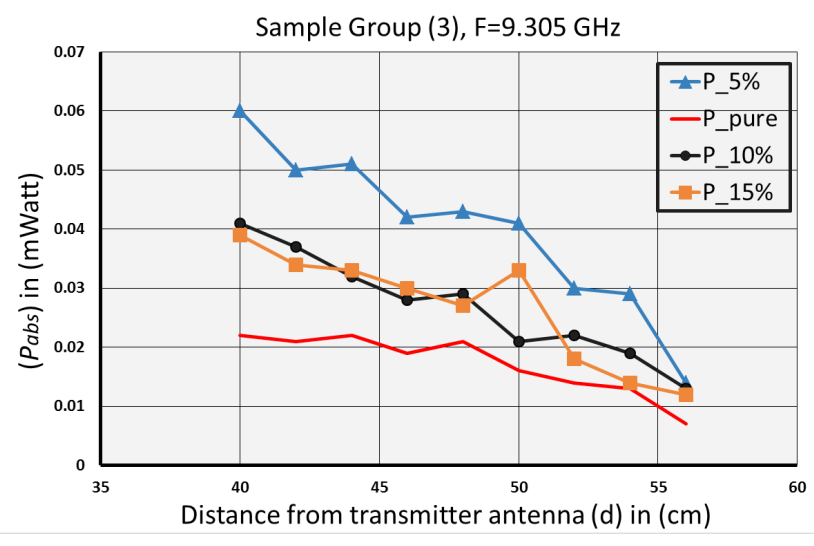

Fig. 18 Power absorption vs. distance at $F=9.305 \mathrm{GHz}$ (Group 3)

indicates that the $5 \%$ river shell ratio tends to oppose the unstable and random behavior noticed in the case of pure polyester composite, $10 \%$ river shell reinforcement, and $15 \%$ reinforcement. The breakdown of the power when MUT of $5 \%$ river shell used as the filler to the pure polyester is clearly noticeable for all cases of distance values at specific operating frequency which is also valid for each board composition in all three groups. 


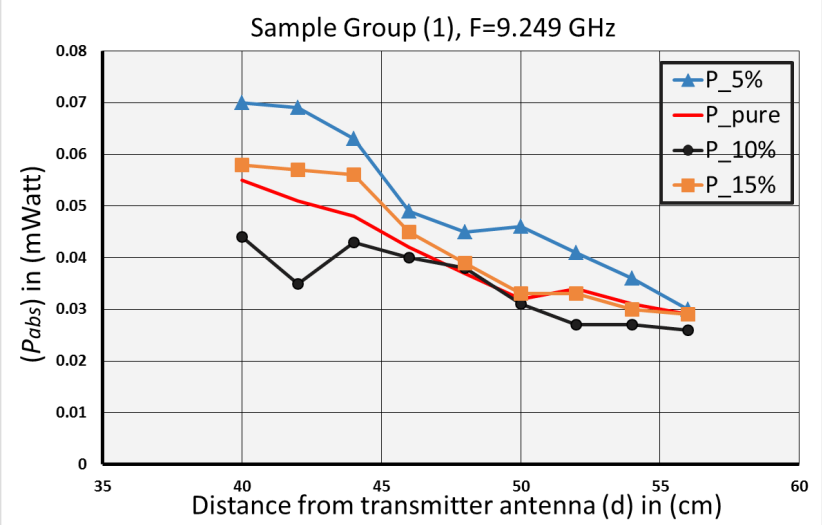

Fig. 19 Power absorption vs. distance at $F=9.249 \mathrm{GHz}$ (Group 1)

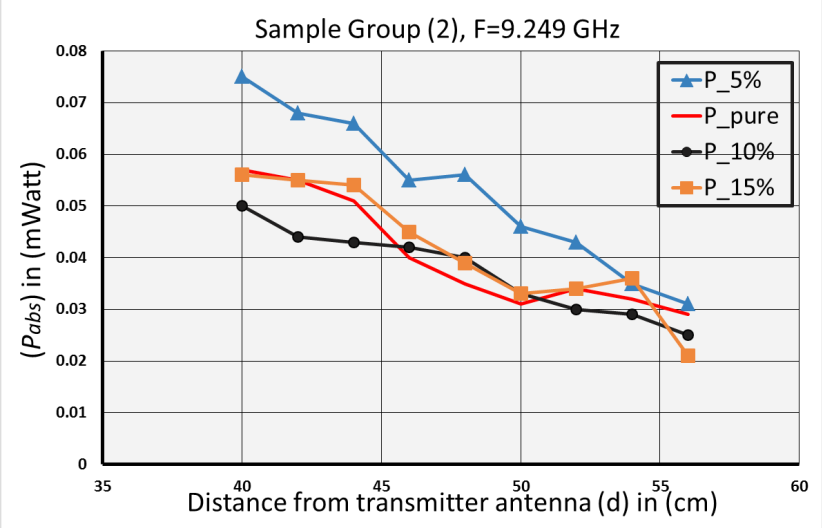

Fig. 20 Power absorption vs. distance at $F=9.249 \mathrm{GHz}$ (Group 2)

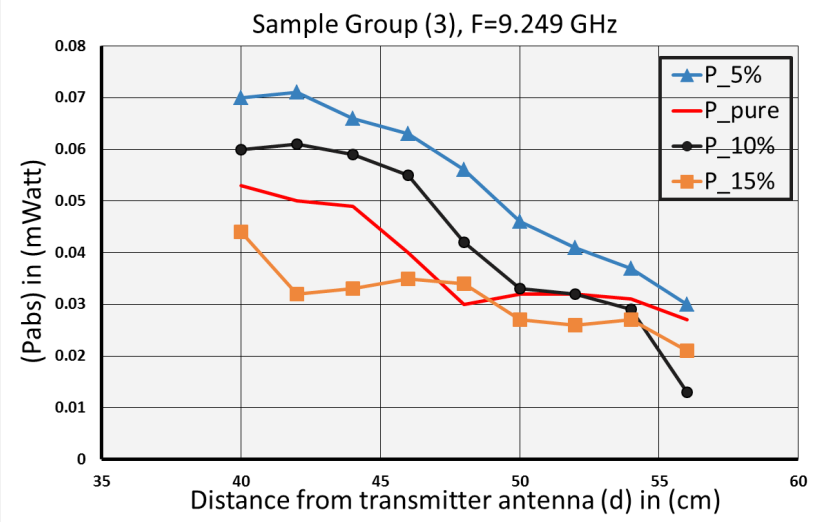

Fig. 21 Power absorption vs. distance at $F=9.249 \mathrm{GHz}$ (Group 3)

\section{Conclusion}

Upon this investigation, the aim of this paper was to practically assess the microwave power absorption in pure polyester and river shell reinforced polyester composites in free-space transmission method. The most significant finding emerged from this work is that the $5 \%$ river shell filler reinforcement amount has proven its priority as the most case of absorbing the power sent by transmitter at specific frequency and within x-band. Priority of $5 \%$

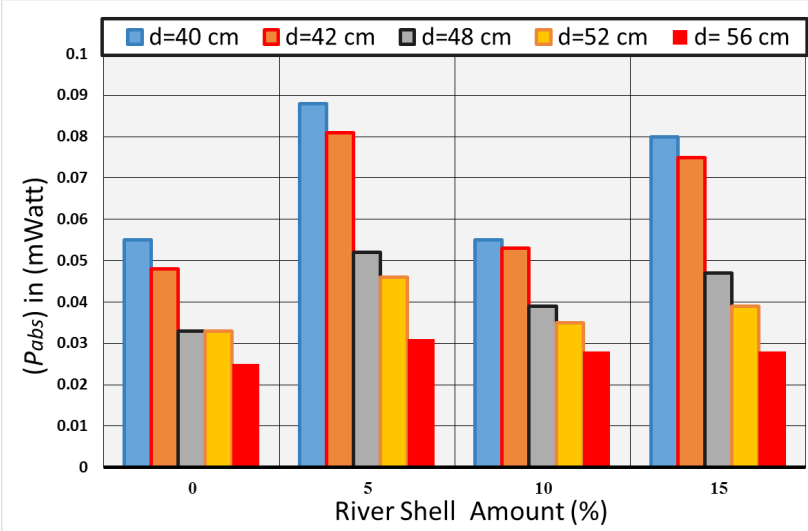

Fig. 22 Power absorption vs. filler amounts for various distances at $F=9.19 \mathrm{GHz}$

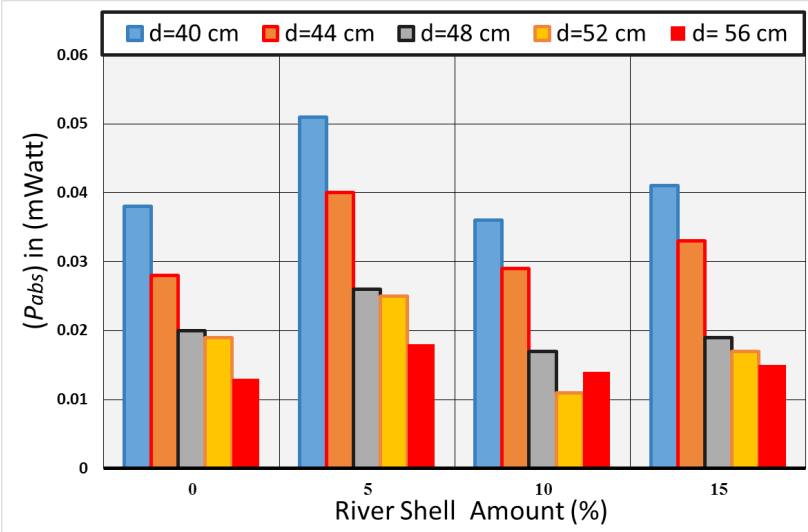

Fig. 23 Power absorption vs. filler amounts for various distances at $F=9.268 \mathrm{GHz}$

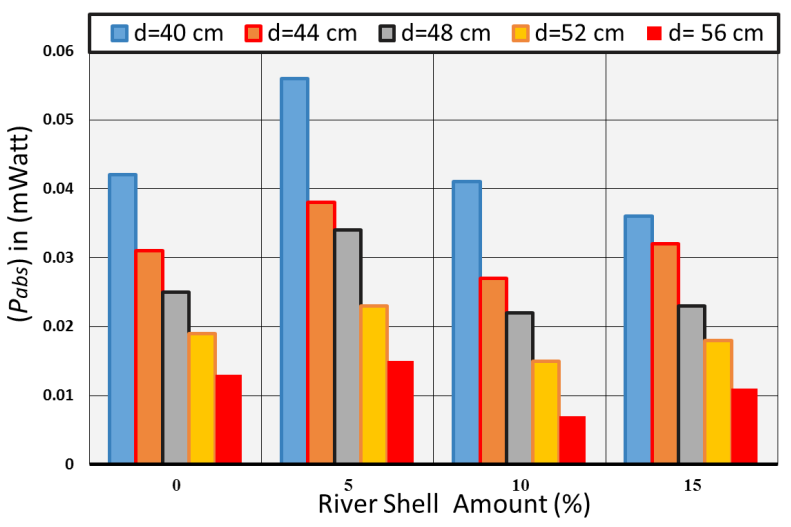

Fig. 24 Power absorption vs. filler amounts for various distances at $F=9.305 \mathrm{GHz}$

has been underpinned by creating three groups of samples in order to provide an adequate statistical evaluation on the boards. For each group, it was the $5 \%$ river shell composition to be the case of recording the most microwave power absorption for all tested frequencies. Moreover, Study implication has shown that as long as testing is within 


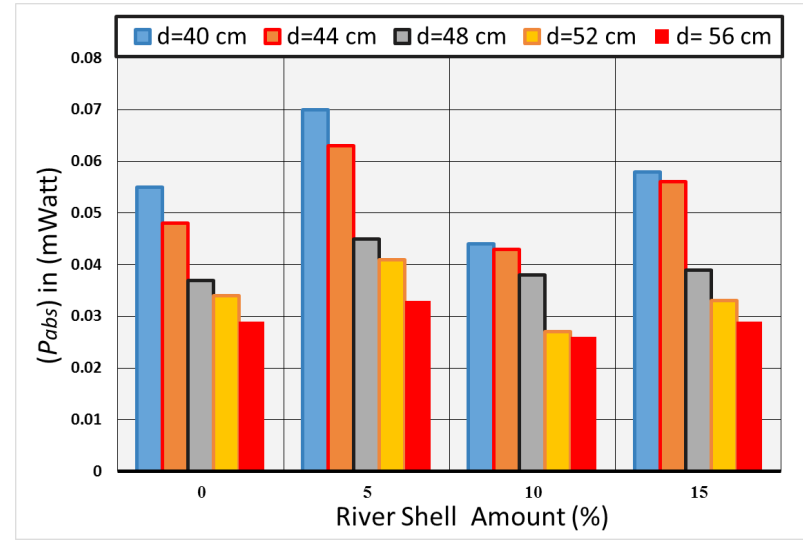

Fig. 25 Power absorption vs. filler amounts for various distances at $F=9.249 \mathrm{GHz}$

\section{References}

[1] Carmona, F., Mouney, C. "Temperature-dependent resistivity and conduction mechanism in carbon particle-filled polymers", Journal of Materials Science, 27(5), pp. 1322-1326, 1992.

https://doi.org/10.1007/BF01142046

[2] Verma, D., Gope, P. C., Shandilya, A., Gupta, A., Maheshwari, M. K. "Coir Fiber Reinforcement and Application in Polymer Composites: A Review", Journal of Material Environment Science, 4(2), pp. 263-276, 2013. [online] Available at: https://www.researchgate.net/profile/Prakash_ Gope/publication/236662055_Coir_Fiber_Reinforcement_ and_Application_in_Polymer_Composites_A_Review/links/ 5717247d08ae497cla570b64.pdf [Accessed: 11 August 2018]

[3] Odusanya, A. A., Bolasodun, B., Madueke, C. I. "Property Evaluation of Sea shell Filler Reinforced Unsaturated Polyester Composite", International Journal of Scientific \& Engineering Research, 5(11), pp. 1343-1349, 2014.

[4] Manohara, V., Sreenivasa, C. G., Bharath, K. N. "Evaluation of Tensile Behavior of Sea Shell-Jute Fabric Reinforced Composite", International Journal of Advanced Research in Mechanical and Production Engineering and Development, 1(3), pp. 141-147, 2014. [online] Available at: https:/www.researchgate.net/profile/Dr_ Bharath_K_N/publication/264999088_Evaluation_of_Tensile_ Behavior_of_Sea_Shell-_Jute_Fabric_Reinforced_Composite/ links/53fb4f370cf2e3cbf566264c/Evaluation-of-TensileBehavior-of-Sea-Shell-Jute-Fabric-Reinforced-Composite.pdf [Accessed: 11 September 2018]

[5] Mahan, H. M., Mahjoob, D. S., Rashid, N. A. "Influence of Silica and Nano Alumina on Mechanical Properties of Glass Fiber Reinforced Epoxy Composite Systems", Journal of Advanced Research in Dynamical and Control Systems, 10(2), pp. 888-895, 2018.

[6] Martin, J. W. "Materials for Engineering", Woodhead Publishing, Abington, Cambridge, UK, 2006. the near-field condition, random and unstable results are recorded. In other word, near-field condition did not reveal any dominant case at which microwave power absorption is to be the highest. Also, the relation between power and distance is inversely proportional.

Finally, using river shell as filler to polyester and investigating its effect on the material under microwave exposure has not been done in previous works. Therefore, this study has its uniqueness in exploring the behavior of microwave signals when passes river shell reinforced polyester composites.

[7] Vignesh, K., Anbazhagan, K., Ashokkumar, E., Manikandan, R., Jayanth, A. "Experimental Analysis of Mechanical Properties of Sea Shell Particles- Polymer Matrix Composite", International Journal of Mechanical and Industrial Technology, 3(1), pp. 13-21, 2015.

[8] Mahan, H. M., Abed, S. A., Shaalan, T., G. "Effect of Silica Particles on The Enhancement of Mechanical Properties and Thermal Conductivity of the Epoxy Composites", Journal of Advanced Research in Dynamical and Control Systems, 10(6), pp. 1818-1821, 2018.

[9] Ghodgaonkar, D. K., Varadan, V. V., Varadan, V. K. "A free-space method for measurement of dielectric constants and loss tangents at microwave frequencies", IEEE Transactions on Instrumentation and Measurement, 38(3), pp. 789-793, 1989.

https://doi.org/10.1109/19.32194

[10] Tamyis, N., Ramli, A., Ghodgaonkar, D. K. "Free space measurement of complex permittivity and complex permeability of magnetic materials using open circuit and short circuit method at microwave frequencies", In: 2002 IEEE Student Conference on Research and Development, Shah Alam, Malaysia, 2002, pp. 394-398. https://doi.org/10.1109/SCORED.2002.1033141

[11] Trabelsi, S., Kraszewski, A. W., Nelson, S. O. "Free-space transmission method for wide-band microwave wheat permittivity measurements", In: 1998 IEEE Conference on Precision Electromagnetic Measurements Digest (Cat. No.98CH36254), Washington, DC, USA, 1998, pp. 536-537. https://doi.org/10.1109/CPEM.1998.700043

[12] Razansky, D., Soldea, D. F., Yankilevich, G., Einziger, P. D. "Estimates on electromagnetic power absorption in highly-lossy configurations", In: 2004 23rd IEEE Convention of Electrical and Electronics Engineers in Israel, Tel-Aviv, Israel, 2004, pp. 193-196.

https://doi.org/10.1109/EEEI.2004.1361122 